\title{
Building identity in online environments: an Information Science perspective
}

\author{
Frances VC Ryan Peter Cruickshank \\ Hazel Hall \\ Edinburgh Napier University, 10 Colinton Road, Edinburgh EH10 5DT, UK \\ f.ryan@napier.ac.uk p.cruickshank@napier.ac.uk \\ h.hall@napier.ac.uk \\ a.lawson@napier.ac.uk
}

\begin{abstract}
The research presented in this poster is concerned with the ways in which people use information to build identities for themselves online with reference to the themes of personal reputation management. To date these two themes have been under-explored together in the research literature, both in general, and from an Information Science perspective. The poster content shares findings related to three areas of identity building: (1) the creation and use of online personas and identities; (2) the use of anonymity and pseudonyms through information sharing - or concealment - practices; and (3) the ways in which the blurring or merging together of participants' private and professional selves. This study used participant diaries and in-depth, semi-structured interviews with 45 UK-based participants. The main finding presented here is that individuals present elements of their online persona or personality using online information, but that they do not do so with the intention of building identity. The findings explored in this presentation are contextualised with reference to identity building in the more formal setting of academic reputation management, i.e. through the use of citations.
\end{abstract}

\section{Keywords}

citation practices, everyday life information seeking, identity, information behaviour and use, online identity, social media, social networking, reputation.

\section{INTRODUCTION}

This poster concerns an aspect of information behaviour and use related to social media with regards to the creation of online identity. The presentation derives from a larger doctoral study that investigates how online information is used in the management and evaluation of personal reputations. It follows the tradition of research into everyday life information seeking (ELIS) (Savolainen, 1995). The findings shared here relate to a research question as applied to the theme of reputation management: How do individuals use information to build identities for themselves online?

\section{LITERATURE REVIEW}

The interdisciplinary nature of the research themes of identity and personal reputation management means that

ASIS\&T 2017, Washington, DC | Oct 27-Nov 1, 2017

Authors retain Copyright. much of the relevant academic literature is dispersed across a number of subject domains. These include, for example: computing; employment research; human computer interaction; human resources management; information systems; marketing; media and communication studies; physical and mental health; and sociology (Ryan, Cruickshank, Hall, \& Lawson, 2015).

There is a large body of research on the role that information plays in the management and evaluation of the academic reputations in general, i.e. that on citation practices (Cronin, 1985; White, 2001). Some of these practices relate to identity building, such as using information for self-promotion and self-censorship. While citation practices do not represent an everyday life information seeking activity, it is possible to match aspects of identity building using citations with human online behaviours and activities that social media users undertake in less formal settings.

\section{RESEARCH DESIGN}

This study used qualitative methods with the use of participant diaries and in-depth, semi-structured interviews. A full account of the research design and its appropriateness to this kind of study was published in 2016 (Ryan et al., 2016). It involved 45 UK-based participants, and data collection took place between October 2015 and January 2016. Participants kept diaries for a week in which they logged everyday information sharing practices on social media that they regarded as having impacts on individual reputations, including questions related to identity. Participants then took part in semi-structured interviews of about one hour in length. Interviews were based on themes from the literature review (Ryan et al., 2015), with diary entries used as additional prompts.

\section{FINDINGS}

Three key themes related to information and identity building and reputation management emerged from the analysis of the data, as outlined below.

The creation and use of online personas: The act of using information to build online identity is largely based on participants' offline identities and personalities, and participants' social media use generally acts as extensions of their everyday lives. They also hint at their "real world selves". However, participants in this study did not consider the act of building an identity online as "building identity". 
Instead, they discussed the idea of building or showcasing different personas or personalities.

The use of anonymity and pseudonyms: Twenty-one of the 45 participants in this study use anonymous accounts or pseudonyms for at least some of their online interactions. With four exceptions, these naming conventions are not deployed to mask offline identities (anonymous accounts), and even then, the four participants using anonymous accounts have shared their "real" identities with at least one person they know in an offline environment.

Of the 18 who use pseudonyms (including one who uses both a pseudonym and an anonymous account), the pseudonyms are associated with the participants" "real" identities. This association takes place either directly or indirectly through bio descriptions, links to other online content managed by the participant, or through the information content itself. Further, pseudonyms are generally deployed as a "username" or as variation of the participants" "real name".

The blurring of selves: The levels of blurring that happen between individuals' private and professional lives can impact if and how different personas are created or showcased through the use of online information. However, most of the participants in this study do not feel that they are intentionally building their identities through the management of this blurring. Rather, they manage how they share information based on how they perceive different platforms should be used, or on the information they believe interests their audience.

Similar to managing the blurring between private and professional information is the idea of managing the blurring between online and offline environments. From an identity standpoint, this can be witnessed in how people represent themselves in one environment or the other. All of the participants in this study feel that their online and offline environments blur together to some extent, and that they are portraying themselves as one person most of the time.

\section{CONCLUSION}

There are some strong alignments between the findings from this research and that of prior research. For example, this research supports the literature related to selfcensorship and the regulation of online information sharing practices (Hagger-Johnson, Egan, \& Stillwell, 2011), the blurring between private and professional personas based on platform use (Ollier-Malaterre, Rothbard, \& Berg, 2013), and the presentation of personas for different audiences (Goffman, 1959). However, there are also some weaker alignments between these findings and the literature, such as the use of anonymity to "experiment" with identity (Bullingham \& Vasconcelos, 2013) and the deliberate concealment of personal information in online profiles (Lingel \& boyd, 2013).

A new theme emerging from this work suggests that the use of information for "building identity" is not an intentional act. Instead, the findings suggest that individuals are not creating an online identity but are managing who they share parts of their offline identity with.

The full doctoral study will investigate this theme in more detail, including the relationship between building online identities, showcasing aspects of personas, and the building and maintenance of personal reputation. This work is expected to be completed in 2017.

\section{ACKNOWLEDGMENTS}

The authors acknowledge the participants in the study.

\section{REFERENCES}

Bullingham, L., \& Vasconcelos, A. C. (2013). "The presentation of self in the online world": Goffman and the study of online identities. Journal of Information Science, 39(1), 101-112.

Cronin, B. (1985). The citation process: The role and significance of citations in scientific communication. London: Taylor Graham.

Goffman, E. (1959). The presentation of self in everyday life. Garden City, N.Y.: Doubleday.

Hagger-Johnson, G., Egan, V., \& Stillwell, D. (2011). Are social networking profiles reliable indicators of sensational interests? Journal of Research in Personality, 45(1), 71-76.

Lingel, J., \& boyd, d. (2013). "Keep it secret, keep it safe": Information poverty, information norms, and stigma. Journal of the American Society for Information Science and Technology, 64(5), 981-991.

Ollier-Malaterre, A., Rothbard, N. P., \& Berg, J. M. (2013). When worlds collide in cyberspace: How boundary work in online social networks impacts professional relationships. Academy of Management Review, 38(4), 645-669.

Ryan, F., Cruickshank, P., Hall, H., \& Lawson, A. (2015). Assessing the available and accessible evidence: how personal reputations are determined and managed online. In Information: interactions and impact (i3) 2015, Robert Gordon University, Aberdeen, Scotland.

Ryan, F., Cruickshank, P., Hall, H., \& Lawson, A. (2016). Personal online reputation: the development of an approach to investigate how personal reputation is evaluated and managed in online environments. In 2nd International Data Information and Information Management Conference (IDIMC) (pp. 98-108). Loughborough: LISU.

Savolainen, R. (1995). Everyday life information seeking: Approaching information seeking in the context of "way of life." Library \& Information Science Research, 17, 259-294.

White, H. D. (2001). Authors as citers over time. Journal of the American Society for Information Science and Technology, 52(2), 87-108. 
The columns on the last page should be of approximately equal length. 